\title{
Single Cell Li-Ion Polymer Battery Charge and Discharge Characterizations for Application on Solar-Powered Unmanned Aerial Vehicle
}

\author{
Parvathy Rajendran ${ }^{1,2, a^{*}}$, Nurul Musfirah Mazlan ${ }^{1, b^{*}}$ and Howard Smith ${ }^{2, c}$ \\ ${ }^{1}$ School of Aerospace Engineering, Universiti Sains Malaysia, 14300 Nibong Tebal, \\ Pulau Pinang, Malaysia
}

${ }^{2}$ Aircraft Design Group, School of Engineering, Cranfield University, MK43 OAL Cranfield, England

aeparvathy@usm.my, ㅌnmusfirah@usm.my, choward.smith@cranfield.ac.uk Keywords:

\author{
LiPo, UAV, Cumulative current, LiPo capacity, Battery testing, Solar-powered UAV.
}

\begin{abstract}
Solar-powered UAV is an alternative way to achieve high endurance and long range UAV flight. However, solar irradiance is not always available during the flight. Thus, secondary power source which is electrical batteries will improve the performance of solar-powered UAV when solar irradiance is not available. Therefore, bench test for LiPo battery is conducted in this paper for the design of solar-powered UAV power system. The impact of operating temperature at various charging and discharging rate on the duration to full charge and discharge and capacity level of a single LiPo battery were assessed. The solar module installed in solar-powered UAV developed by Aircraft Design Group, Cranfield University has to be designed to charge the battery pack at a nominal or maximum rate of $0.129 \mathrm{C}$ and $0.155 \mathrm{C}$ correspondingly. The solar module requires roughly 5.73 hours on nominal charging rate on $30{ }^{\circ} \mathrm{C}$ operating temperature to fully charge capacity level instead of 5.54 hours theoretical predicted. The battery pack will then discharge at cruise flight roughly about $0.071 \mathrm{C}$ to a maximum of $1.685 \mathrm{C}$ if required. If the battery pack is not charged, during cruise flight the battery capacity will deplete completely at about 6.51 hours for the same operating temperature, in contrast to the 6.48 hours based on the theoretical prediction. In addition, the usage of LiPo batteries for operation at high altitudes and/or extreme temperatures without an additional heating or cooling system for these battery packs is not favorable. Thus, it is best to charge at low charging rate and high operating temperature to store and utilize the most capacity from this battery.
\end{abstract}

\section{Introduction}

There is a huge interest in development of hybrid-powered unmanned aerial vehicle (UAV) among research community recently [1]. The combination of battery and solar-powered UAVs has been widely implemented in military application especially surveillance, search and rescue, and border monitoring [1-5]. Thus, focus has moved towards optimizing for long endurance and range so that the UAV can operate mission for days [6-12]. However, solar energy is limited over a day, yet renewable and environment friendly.

Generally, solar-powered UAV will receive solar irradiance during daytime which is converted into energy for propulsion system and charging batteries. At night, when no solar irradiance available, the batteries will supply the for propulsion system to sustain operation. Thus, the performance of battery system is crucial to ensure solar-powered UAVs can continue its mission continuously day and night.

In this work, the Li-lon Polymer (LiPo) battery charge and discharge characterization is done under thermal control environment in order to optimize the performance of these batteries for UAV application. Even though these batteries capabilities are pre-defined by manufacturer, massproduced parts may have lower performance than a prototype or laboratory tested parts. Thus, it is crucial to determine the real-time performance of these batteries based on the requirement of a UAV's operation. This work enables the preferred operational battery system design to accomplish the required endurance and range of the UAV thru charging and discharging batteries at optimum rate and operating temperature. 


\section{Methodology}

The two main functions of a battery are to receive charge and discharge. Therefore, charging and discharging play a major role in the performance and life span of a battery. Thus, identifying the optimum operating temperature, required current and its corresponding flow rate for the battery is essential to maximize any UAV capabilities. In the following section, the details on the LiPo battery and the experimental work done are elucidated.

\section{LiPo Battery}

The chosen battery for this work is a single cylindrical LP-18650-JP-2600 LiPo battery with nominal voltage and capacity of $3.7 \mathrm{~V}$ and $2.6 \mathrm{Ah}$ respectively that may discharge at a maximum rate of $5.2 \mathrm{Ah}$. This single cell battery as shown in fig. 1(a), are one of the 21 cells that have been packed into seven sets of $2.6 \mathrm{Ah}$ at $11.1 \mathrm{~V}$ as shown in fig. 1(b) (unsealed) and 1(c) (completely sealed) below.

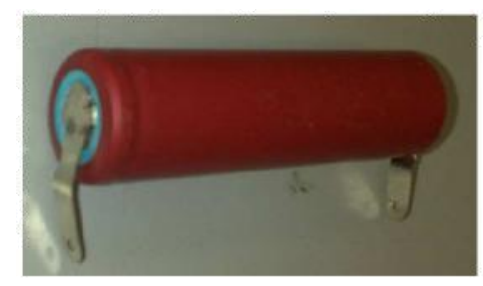

(a)

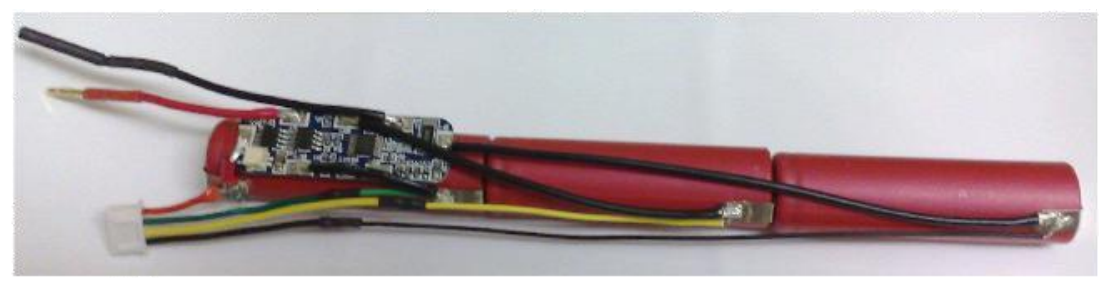

(b)

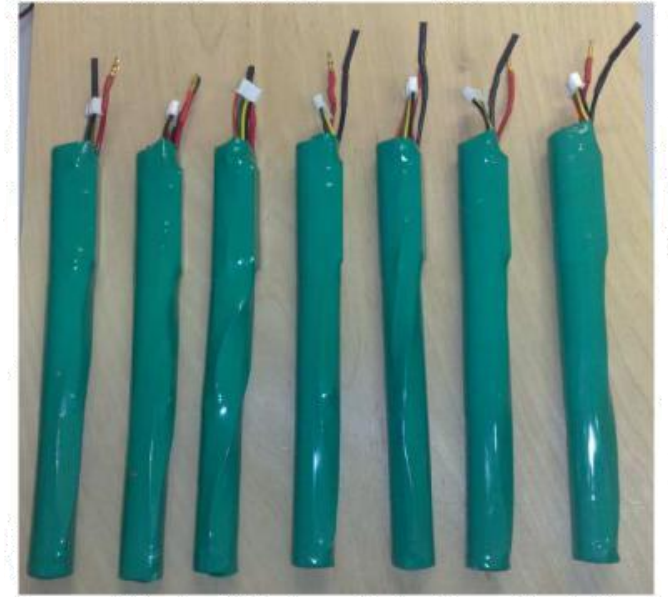

(c)

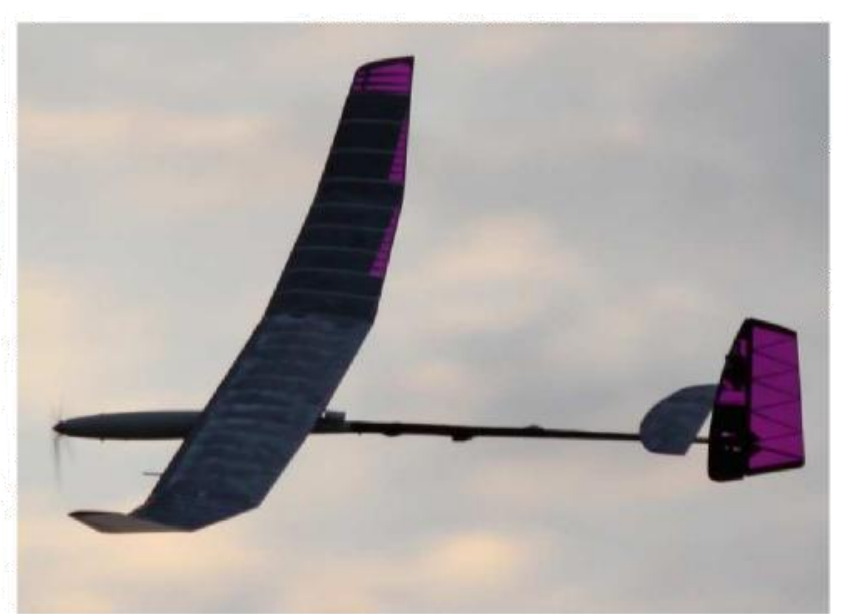

(d)

Fig 1 (a) LP-18650-JP-2600 LiPo Cell (b) Unsealed 2.6 Ah 11.1 V Battery Pack (c) Seven Sets of Battery Pack and (d) Small Solar-powered UAV developed by Cranfield University.

These custom built LiPo battery pack were specifically done for the solar-powered UAV (fig. 1(d)) developed by the Aircraft Design Group, Cranfield University, United Kingdom [6]. In total, when all seven battery packs are connected in parallel, it will be able to supply at maximum current of 36.4 A. However, based on the selected electric motor and propeller, the battery only requires to deliver a maximum current of $35 \mathrm{~A}$.

\section{Experimental Technique}

An experimental set up was conducted to characterize the charge and discharge under temperature controlled environment. Thus, all experimental work was done using an environmental chamber requires liquid nitrogen. The liquid nitrogen has helped to maintain a constant temperature throughout the testing period. The battery will be placed in the testing chamber, while the Bantam LiPo charger charges or discharges the battery cell, live data are recorded via Eagle Tree System Data Logging system. 
Based on the specification from manufacturers, the operating temperature of LiPo battery is between $-20^{\circ} \mathrm{C}$ to $60^{\circ} \mathrm{C}$. The battery's temperature is not allowed to exceed the upper limit of

$70{ }^{\circ} \mathrm{C}$, so the decision to set $40{ }^{\circ} \mathrm{C}$ as the upper limit in this study is made to avoid any undesired chemical reaction or explosion. Moreover, high temperature not only will reduce the performance of the battery but also its life cycle which will affect the study of this research. Besides, the limitation of this LiPo charger is that it can only discharge up to $5 \mathrm{~A}$ which is equivalent of $1.92 \mathrm{C}$ rating for a 2.6 Ah capacity battery pack.

\section{Result \& Discussion}

In this section, the results of the 2.6 Ah single cell LiPo battery charge and discharge characterization is depicted under thermal control environment. The main parameters discussed in this paper includes the trend of charging and discharging duration and cumulative current.

\section{Charging \& Discharging Duration}

As mentioned earlier, the range of temperature for these experiments is set from $0{ }^{\circ} \mathrm{C}$ to 40 ${ }^{\circ} \mathrm{C}$. The duration to charge a single cell LiPo battery over various charging rate at different temperature is plotted in fig. 2(a). The theoretical value of the duration for various charging rate is shown as black dashed line. Ideally, the battery can be fully charged less than 50 minutes when the charging rate $2.0 \mathrm{C}$. Yet, in reality, the duration to charge the LiPo cell is about 2 hours in average even when the charge rate is up to $2.0 \mathrm{C}$. The range of optimum temperature for charging was identified between $30^{\circ} \mathrm{C}$ and $40{ }^{\circ} \mathrm{C}$, but the charging duration is 40 minutes more than theoretical value at $0.25 \mathrm{C}$.

The gap becomes bigger when charge rate increases. At $1.92 \mathrm{C}$, a battery is assumed to have charging period within 31.25 minutes but it is more than 2 hours in reality. The charging duration gap is anticipated due the battery, wiring and charger's internal resistance, which also should increase with the amount of current flow or charging rate. Thus, a high charging rate still requires a considerable amount of time to completely charge the battery.

On the other hand, investigation on the impact of temperature on the charging duration at various charging rate is done as shown in fig. 2(c). When the charging rate is $0.25 \mathrm{C}$, the optimum temperature is close to room temperature before the charging duration increases again beyond the optimum temperature.

Anyway, the optimum temperature is higher as the charging rate rises. But, the impact of temperature on charging duration lessens when the charging rate grows especially above $1.25 \mathrm{C}$. Unlike charging duration, discharging duration in reality for various charging at different temperature is close to theoretical value which can be seen in fig. 2(b). This is due to discharging duration is affected by the battery and wiring's internal resistance only.

Thus, a single cell LiPo battery manages to achieve just below the theoretical value, in contraire to the charging duration which is always higher than the theoretical value. The optimum temperature for discharging battery increases when discharging rate rises as shown in fig. 2(d). Yet, the battery fails to discharge if the discharging rate is high and temperature is low.

\section{Cumulative Current Trend}

Apart from charging or discharging duration of the battery, the total amount of accumulative current is important to identify the amount of capacity stored in the battery out of the charging process. Fig. 3(a) expounds the cumulative current trend of single LiPo battery over charging rate at various temperatures. It is found that the cumulative current is higher when the charging at lower rate and higher temperature. 


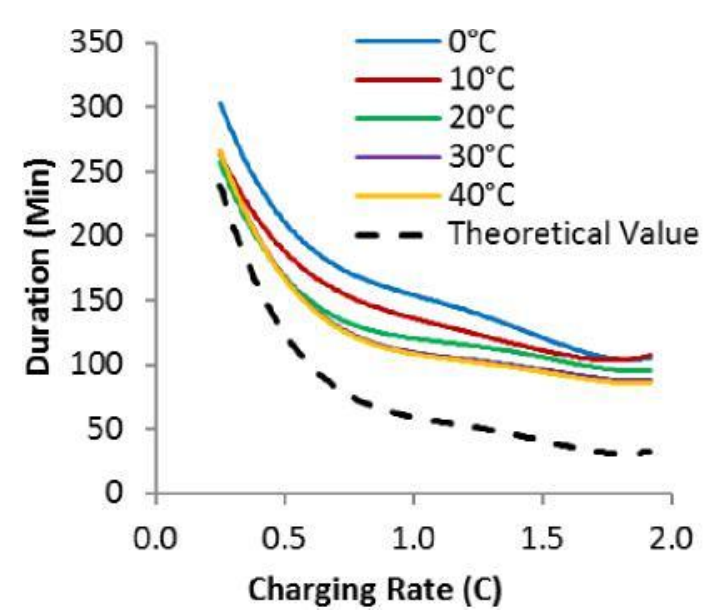

(a)

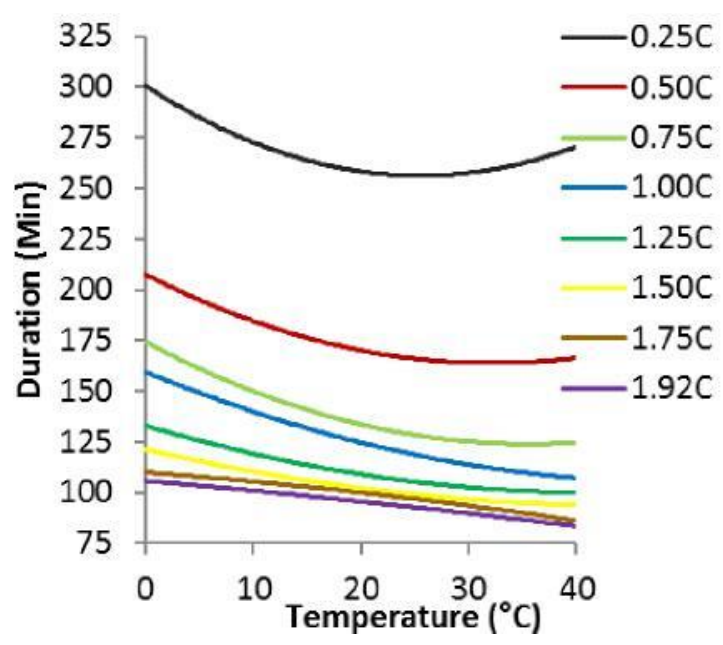

(c)

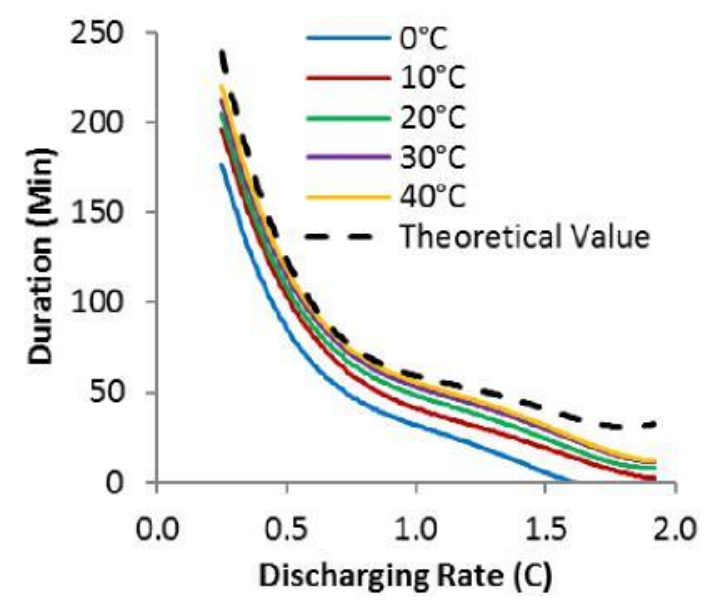

(b)

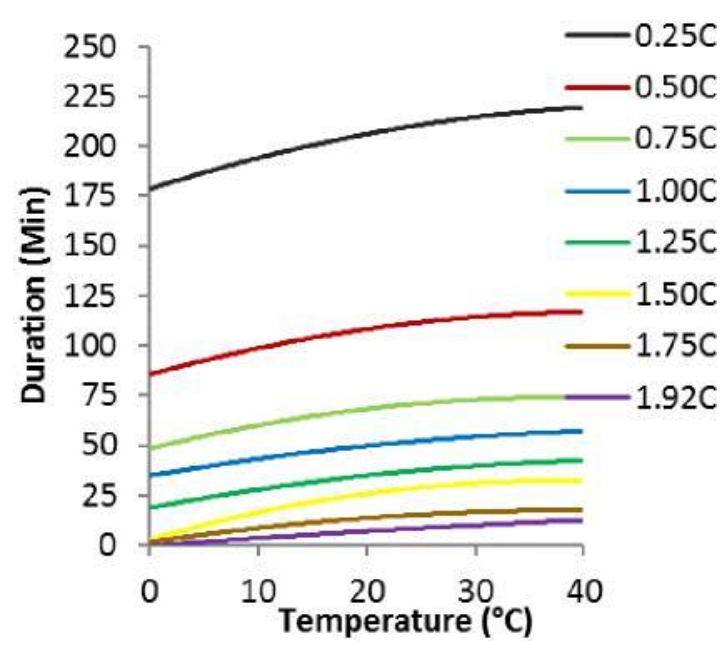

(d)

Fig. 2 LiPo Battery (a) Charging Duration at Various Temperature (b) Discharging Duration at Various Temperature (c) Charging Duration at Various Charge Rate and (d) Discharging Duration at Various Discharge Rate.

At higher temperature, the amount of cumulative current stored in the battery hardly affected by the change in charging rate. At $40{ }^{\circ} \mathrm{C}$ and $0.25 \mathrm{C}$ charging rate, the lost in storage capacity is roughly about $7 \%$. But then, $15 \%$ storage wasted when this battery charged at the same $0.25 \mathrm{C}$ charging rate but at lower temperature of $0{ }^{\circ} \mathrm{C}$.

At lower temperature, the storage capacity level almost halved at higher charging rate as shown in fig. $3(\mathrm{c})$. At $1.92 \mathrm{C}$, the cumulative current is only around $1.6 \mathrm{Ah}$ at $0{ }^{\circ} \mathrm{C}$ but the value is increased to $2.1 \mathrm{Ah}$ when temperature is $30^{\circ} \mathrm{C}$. Thus, it is best to charge at a low charging rate and also at a high operating temperature to be able to store the most capacity in a battery. This analysis indicates that choosing the charging rate with consideration of surrounding temperature is crucial as the UAV flight endurance will be directly affected.

Besides, the cumulative current tendency over discharging rate at different temperature is displayed in fig. 3 (b). Surprisingly, there was no capacity attainable from this battery at $0{ }^{\circ} \mathrm{C}$ operating temperature when discharged at $1.92 \mathrm{C}$. However, at a low discharging rate of $0.25 \mathrm{C}$, the battery manages to deliver a $2.014 \mathrm{Ah}$ and $2.485 \mathrm{Ah}$ cumulative current at $0{ }^{\circ} \mathrm{C}$ and $40{ }^{\circ} \mathrm{C}$ in respective order. These amounts of capacities are fairly close to the theoretical value defined by the manufacturer.

However, the drop in cumulative current level at $1.92 \mathrm{C}$ discharging rate depletes the capacity obtained to merely $38 \%$ of the manufacturer's specification at shown in fig. 3 (d). Here, the 
capacity obtained from a battery reduces with the rising discharging rate and decreasing temperature. Therefore, similar to the battery charging, the discharging is best done in a warm
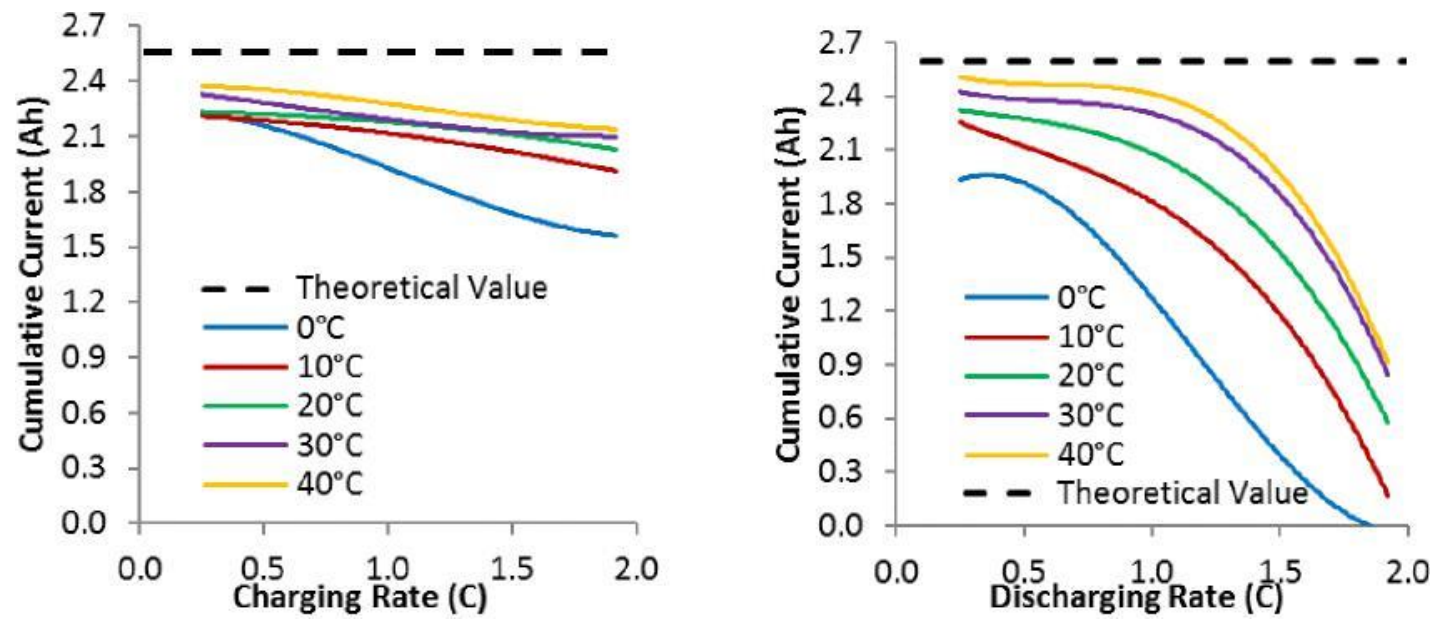

temperature but at a low charging rate.

(a)

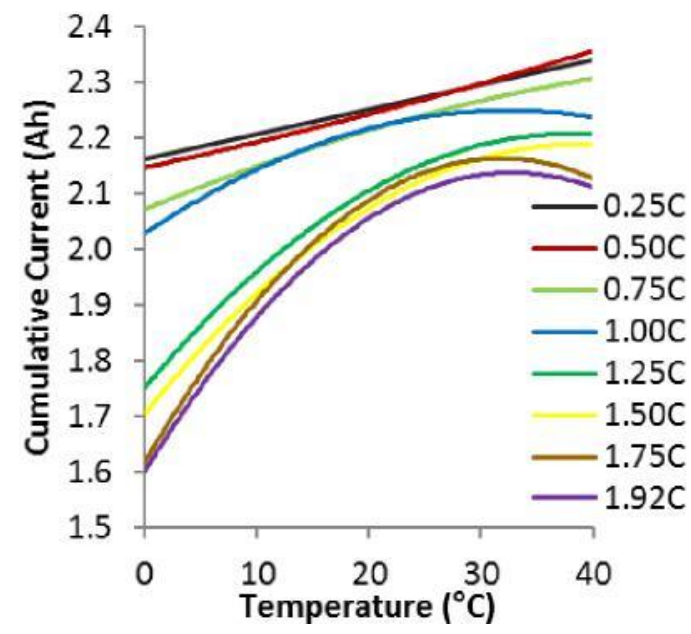

(c) (b)

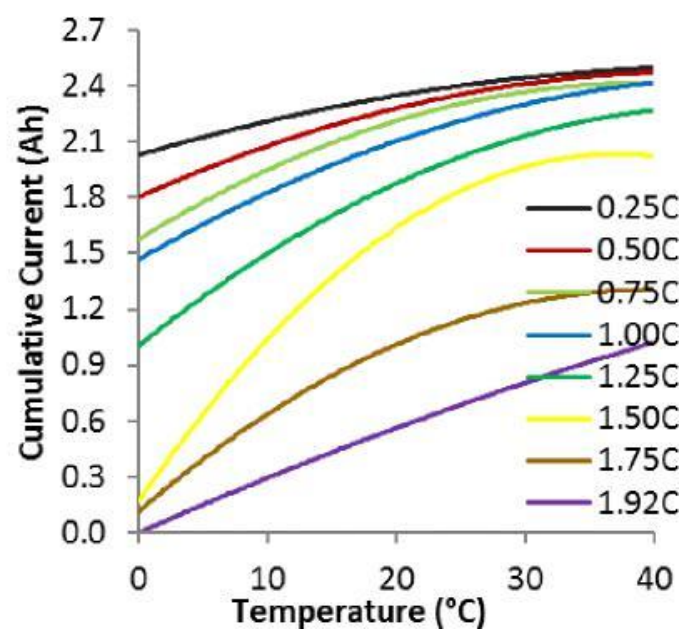

(d)

Fig. 3 LiPo Battery (a) Charging Cumulative Current at Various Temperature (b) Discharging Cumulative Current at Various Temperature (c) Charging Cumulative Current at Various Charge Rate and (d) Discharging Cumulative Current at Various Discharge Rate.

\section{Discussion}

Surprisingly, the charging duration to full capacity of this LiPo cell is maintained at average value of 2 hours approximately which is supposed to be half an hour theoretically at high charging rate. Hence, a high charging rate still requires a considerable amount of time to charge to full capacity completely. So, it is best to avoid charging a battery at charging rate beyond $1 \mathrm{C}$.

Therefore, for the solar module installed in solar-powered UAV developed by Aircraft Design Group, Cranfield University was designed to charge the battery pack at a nominal or maximum rate of $0.129 \mathrm{C}$ and $0.155 \mathrm{C}$ correspondingly. Thus, the solar module requires roughly 5.73 hours on nominal charging rate on $30{ }^{\circ} \mathrm{C}$ operating temperature to fully charge capacity level instead of 5.54 hours theoretical predicted.

The battery pack will then discharge at cruise flight roughly about $0.071 \mathrm{C}$ to a maximum of $1.685 \mathrm{C}$ if required. If the battery pack is not charged, during cruise flight the battery capacity will 
deplete completely at about 6.51 hours for the same operating temperature, in contrast to the 6.48 hours based on the theoretical prediction.

\section{Conclusion}

The LiPo battery is not able to charge and discharge properly towards the lower end temperatures as specified by the manufacturer. Yet, the optimum temperature for charging and discharging the LiPo battery is slightly more than room temperature. This clearly states that the usage of LiPo batteries for operation at high altitudes and/or extreme temperatures without an additional heating or cooling system for these battery packs is not favorable. Thus, it is best to charge at low charging rate and high operating temperature to store the most capacity in a battery.

\section{Acknowledgement}

This publication was supported by Universiti Sains Malaysia Short Term Grant No. 304/PAERO/60312047 and 304/PAERO/60313022.

\section{References}

[1] X.F. Zhu, Z. Guo, Z.X. Hou, Solar-powered airplanes: A historical perspective and future challenges, Progress in Aerospace Sciences, 71 (2014) 36-53.

[2] V. De Devabhaktuni, M. Alam, S.S.S.R. Depuru, R.C. Green, D. Nims, C. Near, Solar energy: Trends and enabling technologies, Renewable and Sustainable Energy Reviews, 19 (2013) 555564.

[3] H. Smith, P. Rajendran, Review of the Elementary Aspect of Small Solar-powered Electric Unmanned Aerial Vehicles, Aust. J. Basic \& Appl. Sci., 8 (2014) 252-259.

[4] S.G. Kontogiannis, J.A. Ekaterinaris, Design, performance evaluation and optimization of a UAV, Aerospace Science and Technology, 29 (2013) 339-350.

[5] A. Chaves, A. T. Bahill, Comparison of Risk Analysis Approaches and a Case Study of the Risk of Incorporating Solar Photovoltaic Systems into a Commercial Electric Power Grid, Systems Engineering, 17 (2014) 89-111.

[6] P. Rajendran, H. Smith, The development of a Small Solar Powered Electric Unmanned Aerial Vehicle Systems, Applied Mechanics and Materials, 465-466 (2014) 345-351.

[7] S. Jashnani, T.R. Nada, M. Ishfaq, A. Khamker, P. Shaholia, Sizing and preliminary hardware testing of solar powered UAV, The Egyptian Journal of Remote Sensing and Space Sciences, 16 (2015) 189-198.

[8] P. Rajendran, H. Smith, Review of Solar and Battery Power System Development for SolarPowered Electric Unmanned Aerial Vehicles, Advanced Materials Research, 1125 (2015) 641-647.

[9] X.Z. Gao, Z.X. Hou, Z. Guo, R.F. J.X. Liu, X.Q. Chen, Energy management strategy for solarpowered high-altitude long-endurance aircraft, Energy Conversion and Management, 70 (2013) 20-30.

[10] F. Fazelpour, M. Vafaeipour, O. Rahbari, R. Shirmohammadi, Considerable parameters of using PV cells for solar-powered aircrafts, Renewable and Sustainable Energy Reviews, 22 (2013) 81-91.

[11] P. Rajendran, H. Smith, Implications of longitude and latitude on the size of solar-powered UAV, Energy Conversion Management, 98 (2015) 107-114.

[12] X.Z. Gao, Z.X. Hou, Z. Guo, R.F. Fan, X.Q. Chen, The equivalence of gravitational potential and rechargeable battery for high-altitude long-endurance solar-powered aircraft on energy storage, Energy Conversion and Management, 76 (2013) 986-995. 

2017-01-31

Single cell Li-lon polymer battery charge and discharge characterizations for application on solar-powered unmanned aerial vehicle

Rajendran, Parvathy

Trans Tech Publications

Rajendran P, Mazlan NM, Smith H. (2017) Single cell Li-lon polymer battery charge and discharge characterizations for application on solar-powered unmanned aerial vehicle. Key Engineering Materials, Volume 728, 2017, pp. 428-433

http://dx.doi.org/10.4028/www.scientific.net/KEM.728.428 Downloaded from Cranfield Library Services E-Repository 